УДК 069.017(470+571)

DOI: $10.32340 / 2414-9101-2021-4-36-44$

Е. В. Шехватова

Алтайский государственный институт культуры (Барнаул, Россия)

01jenia@mail.ru

\title{
СОВРЕМЕННОЕ СОСТОЯНИЕ И ПЕРСПЕКТИВЫ РАЗВИТИЯ ЧАСТНЫХ МУЗЕЕВ РОССИИ
}

Аннотация. Кратко охарактеризовано современное состояние российских частных музеев, действующих в составе национальной музейной сети. Проанализирован состав актуальных проблем в области теории и практики отечественного частного музейного дела (назревшая потребность в конкретизации отраслевой терминологии, отсутствие единой критериальной системы классификации негосударственных музеев, возросшие экономические риски и неопределённость нормативно-правового регулирования деятельности частных музеев). Изложен авторский вариант определения понятия “частный музей” как публичной институции, представленной музеями и учреждениями музейного типа, созданными усилиями частных лиц и развивающимися за счёт их средств, с целью актуализации коллекций, сформированных в соответствии с интересами их создателей. Представлены данные о количественной динамике частных музеев в России, рассмотрены специфические черты частного музея.

Ключевые слова: музеи России, частный музей, музееформирующие процессы, музейная сеть, музейный мир.

Современная российская музейная сеть представлена значительным разнообразием учреждений, среди которых музеи различных форм собственности и профильной принадлежности. Общее число государственных музеев Российской Федерации по данным отчета Главного информационно-вычислительного центра Министерства культуры РФ за 2020 г. составило 2920 (в т. ч. филиалов и структурных подразделений) [1]. Заметна динамика прироста общего числа музеев: с 2000 г. (1382 музея) [2, с. 241] - более чем в 2 раза, с 2012 г. (2553 музея) [1] - на 308 музеев. В своде годовых сведений о деятельности музеев Главного информационно-вычислительного центра Министерства культуры РФ отмечено, что в него включены музеи всех форм собственности, однако непосредственно в документе нет разграничения по формам собственности. Как правило, учету поддаются государственные и муниципальные музеи.

Важной частью современного музейного мира России является группа частных музеев. Данная группа музеев наиболее подвижна и «чутко фиксирует и отражает происходящие в обществе и культуре изменения» [3, с. 25], но, несмотря на это недостаточно изучена и разработана, в первую очередь, по причине фрагментарности данных. Работа по их учету и классификации была инициирована в конце первого десятилетия XXI века и продолжается на настоящем этапе. В каталоге некоммерческой организации «Ассоциация содействия частным музеям России» за 2020 г. зафиксированы 482 частных музея на территории 85 регионов [4], но точное их количество неизвестно.

В связи с возрастающей актуальностью частных музеев как культурной формы, в 2005 г. при Международном совете музеев (ИКОМ) была создана Ассоциация частных музеев и коллекционеров. В ноябре 2018 г. была создана некоммерческая организация «Ассоциация содействия частным музеям России» с целью объединения их владельцев, а также открытия новых горизонтов сотрудничества для совместной работы и обмена опытом. Данной ассоциацией ведется каталог со справочными материалами о частных музеях страны [4]. Однако данная информация является фрагментарной, в некоторых случаях статистически недосто- 
верной. Происходит это потому, что сотрудники ассоциации оперируют лишь данными, предоставленными самими владельцами музеев, часто субъективными, а также не подвергают полученные данные строгому критериальному отбору. В результате, в список попадают общественные, корпоративные музеи, музеи различных ведомств и т. д.

Размытость, слабая достоверность и фрагментарность информации о частных музеях страны и ее отдельных регионов, в том числе статистическая, объясняется их терминологической, классификационной, правовой и экономической неопределенностью. По этой причине следует рассмотреть и проанализировать их отдельно.

Терминологическая неопределенность заключается в отсутствии данного понятия в действующем музейном законодательстве. В настоящее время в музееведении для определения музеев, не являющихся подконтрольными государству, часто используется термин «частные музеи». Таким образом, частные музеи отождествляются с негосударственными музеями несмотря на то, что группа негосударственных музеев гораздо шире и включает в себя, помимо частных, корпоративные, общественные и церковные музеи.

Когда речь идет о такой нерегламентированной категории, как «частный музей», необходима переоценка самих критериев его изучения. Такой прецедент пересмотра термина «музей» присутствовал в международной музейной практике, когда Международным советом музеев (ИКОМ) было отмечено, что «помимо “музеев" как таковых, отвечающими этому определению» [5] считаются и некоммерческие галереи, культурные центры и любые другие учреждения «имеющие некоторые или все характеристики музея» [5].

В музееведческой терминологии к группе частных музеев принято относить организации, «принадлежащие частным лицам, созданные их усилиями и поддерживаемые их средствами» [6, с. 64]. Такое определение является достаточно условным, поскольку содержит лишь общую информацию об учредителе, следующую из наименования категории. Предполагается, что функциональное содержание рассматриваемой категории музеев выражено в самом понятии «музей», а их специфика заключается лишь в правовом аспекте.

На современном этапе категория «частный музей» объединяет социокультурные учреждения различной степени музейности - «традиционные» музеи, обладающие коллекциями и осуществляющие основные музейные функции (документирования, хранения и изучения, образовательно-воспитательную); учреждения музейного типа, для которых наличие собственных коллекций не является обязательным критерием и которые осуществляют лишь отдельные функции и направления деятельности музея; организации, использующие в своем названии категорию «музей» в качестве знака, бренда. Как справедливо заметил А. М. Кулемзин, «имеются частные музеи, которые не являются ни учреждениями, ни предприятиями, а считаются разновидностью собственности владельца. Тем не менее, они выполняют функции, присущие музею. Из этого следует, что музей не учреждение, а определенная организационная структура. Но точнее музей - это социальный институт для осуществления определенных и изменяющихся функций» [7].

Автор под категорией «частный музей» понимает публичную институцию, представленную музеями и учреждениями музейного типа, созданных усилиями частных лиц и развивающихся за счёт их средств, с целью актуализации коллекций, сформированных в соответствии с интересами их создателей. Следует отметить, что, как правило, документирующая деятельность частных музеев определена эстетическими, культурными, научными интересами ее создателя, а в основе коммуникативной деятельности лежит аутентичная коллекция и не доминирует коммерческая составляющая.

Такое расширительное толкование частного музея обусловлено фактом его формообразования. Частный музей в современном виде представляет собой новое явление и проходит стадию формирования в качестве культурной формы, а потому применяет различные варианты собственной презентации. Со временем, когда частный музей как культурная форма пройдет стадию адаптации, согласно периодизации процесса становления культурной формы Е. А. Поляковой [8, с. 129], данная группа учреждений станет более определенной и устоявшейся. 
Существует также классификационная неопределенность. В настоящее время частные музеи классифицируют по общим, уже утвержденным в музееведении параметрам, не всегда позволяющим отразить их сущность и выявить закономерности развития. Основными, принятыми в музеологии классификационными принципами являются: принцип профильной классификации, принцип общественного назначения, принцип классификации по характеру хранимого наследия, принцип административно-территориальной принадлежности [9]. В основе данных принципов лежат институциональные признаки, являющиеся формальными критериями, позволяющими ориентироваться в музейном мире. Возникающие в настоящее время, часто «гибридные», формы музеев уже не вполне вписываются в существующие традиционные классификационные схемы. Существующая классификация не позволяет в достаточной степени «достичь понимания сути музея как феномена и как культурной формы» $[10$, c. 75]. Несмотря на это, частным музеям не следует отказываться от уже сложившихся систем классификации, поскольку они содержат функционально важные принципы, позволяющие ориентироваться в тематическом разнообразии музеев.

В настоящее время исследователями разрабатываются альтернативные классификации музеев. Так, О. С. Сапанжа, развивая классификацию А. Я. Флиера с позиции морфологии музейности, выделяет подвергающиеся сохранению области жизнедеятельности человека [11, с. 10-12]. Предполагается, что такая структура может сформировать понимание того, что «собственно является предметом специфического интереса (с процессуальной, а не только предметно-материальной точки зрения)» $[11$, с. 8$]$ и обозначить те области жизнедеятельности, которые старается «задокументировать» субъект культуры. Классификация, основанная на морфологии, позволяет также содержательно сгруппировать музеи с учетом социально важной информации, транслируемой посредством материальных памятников.

Встраивание частных музеев в классификационные рамки происходит проблематично даже по профильному признаку, в основном по причине их законодательной нерегламентированности, а также отсутствия профильных установок при комплектовании фондов. В отношении принципа классификации по характеру хранимого наследия среди частных музеев существует тенденция преобладания группы коллекционных музеев над ансамблевыми, что связано с тем, что морфологической основой частного музея является частное коллекционирование (характер деятельности частного музея, как правило, определяет наличествующая коллекция).

В большей степени частным музеям подходит разрабатываемая классификация, основанная на морфологии музейности, которая позволяет их содержательно группировать. Так, частные музеи быта различных эпох (музей «Мир времени», г. Барнаул и др.), музеи определенных категорий предметов (музей авто-мототехники «Ретропарк», г. Новокузнецк и др.) можно отнести к области социальной организации и регуляции и т. д. Формирование индивидуальной классификационной схемы для рассматриваемой категории музеев в настоящее время не представляется возможным, поскольку данная группа учреждений находится в стадии своего формирования в качестве культурной формы.

В качестве проблемы следует также отметить отсутствие устоявшегося диалога между частными музеями и государством. Частные музеи, в отличие от государственных, не имеют поддержки в виде налоговых, таможенных и иных преференций. В 2017 г. министром культуры Российской Федерации В. Р. Мединским было подписано решение Коллегии Министерства культуры РФ «О развитии частных музеев в Российской Федерации», в котором была признана важность частных музеев и необходимость построения диалога с ними и был утвержден ряд мер, направленных на их учет и популяризацию [12]. Положительной тенденцией явилось также анонсирование Министерством культуры РФ в конце 2020 г. создание реестра частных музеев, куда вошли около 500 таких организаций и Программы развития частных музеев на 2021-2023 гг. В открытом доступе данный документ не появился. Министерство культуры РФ сообщает, что упомянутые документы «не являются нормативными 
правовыми актами» [13]. Также заместитель директора Департамента музеев и внешних связей Н. В. Чечель разъясняет, что реестр был создан для оценки масштабов, содержания и состояния коллекций, хранящихся в частных музеях, и не предполагает наделение включенных в перечень частных музеев особыми правами и обязанностями [13]. Таким образом, Программа развития частных музеев уже составлена и будет официально опубликована в течение 2021 года, а реестр частных музеев имеет закрытый формат, предназначенный для внутренней работы Министерства культуры. Заявленные цели данных мероприятий включение частных музеев в единое музейное пространство - пока остаются без реализации.

Серьезной проблемой частных музеев Западной Сибири является недостаточное понимание необходимости открытости своих учреждений для социума. Обращает на себя внимание тот факт, что большинство частных музеев практически закрыты в информационном пространстве, как для коллег, так и для аудитории. Это не дает возможности потенциальным инвесторам, спонсорам, благотворителям, попечителям и другим субъектам инициировать поддержку и принимать участие в финансировании частных музеев. Только часть из них имеет представительство в информационно-телекоммуникационной сети Интернет (официальный сайт или аккаунты в социальных сетях), а также только половина от общего числа музеев имеют стабильный график работы учреждения. С учетом начавшейся в стране цифровизации, а также в связи со сложившейся с 2020 года пандемической ситуацией, когда многие учреждения культуры утратили живую связь со своими посетителями, зрителями, слушателями, лишь в режиме онлайн частные музеи страны могут поддерживать связь со своей аудиторией. В ситуации, когда значительное число частных музеев страны и региона не имеют такой связи, они вовсе могут выпасть из социокультурного пространства.

Кроме терминологической и правовой, существует также экономическая неопределенность в деятельности частных музеев в России: аренда земли и зданий, содержание музея, управленческие и кадровые вопросы - все содержит часто неразрешимые проблемы. Следует обратить внимание на проблемы управления частными музеями, поскольку они присущи всем учреждениям культуры, вне зависимости от принадлежности собственнику. На это указывают ведущие специалисты в области менеджмента в сфере культуры, в частности, О. П. Неретин [14], Г. Л. Тульчинский и Е. Л. Шекова [15]. Специфику менеджмента в сфере культуры составляет активное привлечение не только посетителей в культурный процесс, но и доноров, инвесторов. Г. Л. Тульчинский и Е. Л. Шекова указывают на «вопиюще низкий уровень культуры управления в сфере культуры» [15, с. 37]. Это в полной мере относится к частным музеям, в которых основатели часто не имеют не только специального образования, но далеки от области культуры. Многие основатели частных музеев осуществляют эту деятельность самостоятельно, не имея возможности или желания привлекать к ней специалистов. Многие руководители частных музеев не знают и не используют возможности дополнительного финансирования своих музеев, такие как спонсорство, меценатство, патронаж, грант, фандрейзинг и др.

При всей сложности основания и высокой неопределенности в различных областях, все же наблюдается высокая динамика создания частных музеев в стране. На рисунке 1 приведена хронология образования частных музеев России, составленная на основании результатов исследования автора. Можно сделать вывод, что наиболее активно частные музеи стали появляться с 2006 г. - в среднем по 10 музеев в год. Пик образования частных музеев в стране пришелся на 2014-2019 гг.

Автором выявлено, что на территории Российской Федерации функционируют 351 частный музей. Частные музеи каждого из субъектов Российской Федерации имеют свою специфику, но для них характерны и общие черты. 


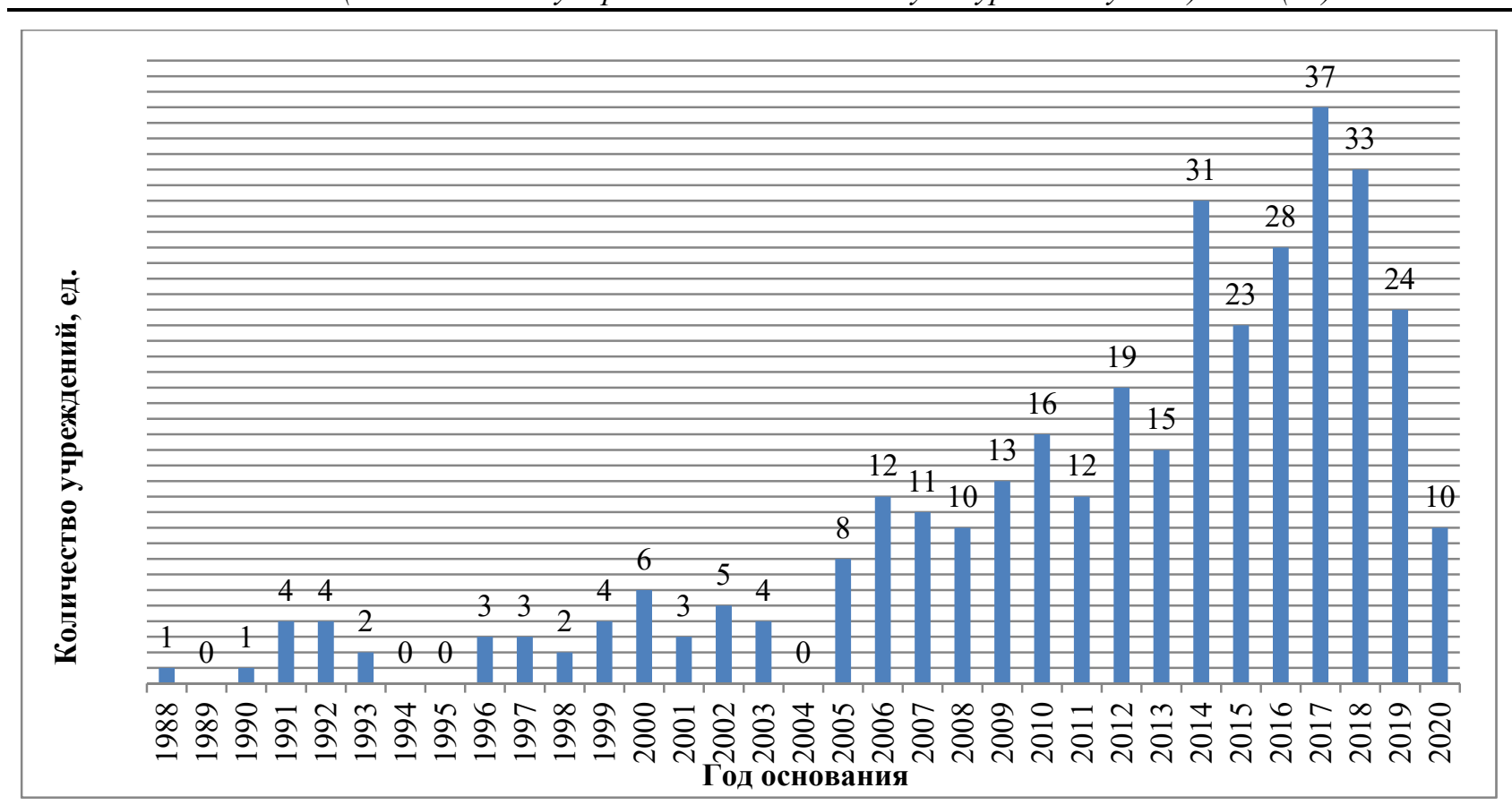

Рис. 1. Хронология образования частных музеев России

В Центральном федеральном округе выявлено 150 частных музеев. На территории федерального округа наблюдается относительно однородное распределение частных музеев по профильной принадлежности - встречаются учреждения культуры всех основных профильных групп с небольшим преобладанием гуманитарной и отраслевой профильных групп. В отдельных регионах можно выявить преобладание какой-либо одной профильной группы, так в Костромской области среди частных музеев преобладают музеи декоративноприкладного искусства, в Ярославской - отраслевые и т. д.

На территории округа встречаются частные музеи со всеми основными типами экспозиции (систематические, ансамблевые, тематические), но преобладающей экспозиционной формой является систематическая. Это связано с тем, что в округе располагается большое количество учреждений, выставляющих частные типологические коллекции, состоящие из однотипных предметов. Основными формами работы в частных музеях исследуемого региона являются интерактивные экскурсии и мастер-классы.

Цифровизация музеев в Центральном федеральном округе развита недостаточно. Подавляющее большинство частных музеев г. Москва, Московской области и других регионов округа, как правило, имеют представительства в сети Интернет, но внутренняя деятельность музеев, их работа с посетителями не сопровождаются цифровыми технологиями. В целом, можно заключить, что цифровизация в деятельности частных музеев округа развита слабо. Исключение составляют несколько крупных музеев г. Москвы, в том числе «Музей русской иконы», музей современного искусства «Гараж». Самым технологичным музеем России является «Еврейский музей и центр толерантности» (г. Москва).

Средняя посещаемость частных музеев округа невысокая - около 1 тыс. посетителей в год по данным каталога Ассоциации частных музеев России [4]. Исключением являются крупные частные музеи г. Москва, посещаемость которых достигает 25 тыс. человек в год. Одним из самых посещаемых в стране является музей современного искусства «Гараж»в среднем ок. 1 млн посетителей в год [16].

В Северо-Западном федеральном округе выявлено 68 частных музеев. В нем также, как и в Центральном федеральном округе, располагаются музеи различной профильной принадлежности, но менее однородно. На территории округа в целом превалируют этнографическая и художественная (декоративно-прикладного искусства) направленности. В некоторых регионах округа количество выявленных частных музеев данной направленности достигает 50 \%, 
например, в Архангельской, Вологодской, Калининградской областях, республике Карелия. Присутствуют на территории округа также историко-бытовые, комплексные музеи.

На территории округа встречаются частные музеи со всеми основными типами экспозиции (систематические, ансамблевые, тематические), но преобладающей экспозиционной формой является ансамблевая, что связано с преобладанием комплексных и этнографических частных музеев. Основной формой работы с посетителями является интерактивная экскурсия (обзорная или тематическая). В большинстве учреждений проводятся тематические мастерклассы. В ряде музеев применяются неклассические формы работы с посетителями. Так, в Санкт-Петербургском музее игрушки действует арт-терапевтическая и творческая студия, в музее современного искусства «Эрарта» - интерактивные тематические программы, включающие квесты, спектакли и т. д.

Средняя посещаемость частных музеев округа такая же невысокая, как и в Центральном федеральном округе - от 1 до 3 тыс. посетителей в год по данным каталога Ассоциации частных музеев России. В г. Санкт-Петербург посещаемость выше, но не превышает 15-16 тыс. человек в год. Исключением являются крупный частный музей современного искусства «Эрарта», посещаемость которого достигает 500 тыс. человек в год [4].

В Северо-Кавказском федеральном округе выявлено 4 частных музея. Выявленные музеи принадлежат к гуманитарной профильной группе - исторический (этнографический) и художественный (изобразительного искусства) музеи. Основной формой работы с посетителями в рассмотренных учреждениях является интерактивная экскурсия. Посещаемость частных музеев округа низкая (не превышает 500 человек в год), за исключением художественного музея русского интемпоризма в г. Железноводск Ставропольского края, где она составляет 5 тыс. человек в год [4].

В Южном федеральном округе выявлен 21 частный музей. На территории округа располагаются частные музеи гуманитарной профильной группы, музеи науки и техники, отраслевые и комплексные музеи. Преобладающими являются исторические (этнографические), художественные (изобразительного и декоративно-прикладного искусства) музеи. Основными формами работы с посетителями в выявленных музеях являются экскурсия и мастер-класс.

В плане посещаемости на территории округа существуют музеи, как с низкой, так и с относительно высокой посещаемостью - от 500 человек до 20 тыс. человек в год. Частные музеи с относительно высокой посещаемостью расположены в крупных городах округа, в т. ч. курортных, - г. Волгоград (музей И. В. Сталина, музей шоколада «Шоколадушка» ок. 10 тыс. чел. в год [4]) г. Краснодар (дом творчества В. Высоцкого - ок. 9 тыс. чел. в год [4]), г. Ростов-на-Дону (музей современного изобразительного искусства на Дмитровской ок. 10 тыс. чел. в год [4]), г. Сочи (музей керамики Ю. Новикова - ок. 5 тыс. чел. в год [4]), г. Элиста (музей «Уникальная Калмыкия» - ок. 15 тыс. чел. в год [4]), г. Ялта (музей автомобильного искусства - ок. 20 тыс. чел. в год [4]).

В Приволжском федеральном округе выявлены 30 частных музеев, среди которых преобладает художественный (изобразительного и декоративно-прикладного искусства) профиль. Частные музеи округа в своем большинстве во взаимодействии с посетителями практикуют разнообразные интерактивные формы работы, основными из которых являются интерактивная экскурсия и мастер-класс. Применяются также квесты, творческие мастерские, мультимедийные интерактивные мероприятия, проводятся фестивали. Посещаемость относительно высокая - в среднем ок. 5 тыс. человек в год [4]. Наиболее посещаемыми частными музеями округа являются «Музей вятского самовара» (г. Киров, ок. 10 тыс. чел. в год [4]), Марийский мемориальный народный музей истории ГУЛАГа (г. Йошкар-Ола, до 8 тыс. чел. в год [4]), «Музей чак-чака» (г. Казань, ок. 22,5 тыс. чел. в год [4]), Музей-галерея La boheme artistique (г. Ижевск, ок. 100 тыс. чел. в год [4]), «Музей истории шоколада» (г. Ижевск, ок. 20 тыс. чел. в год [4]).

В Уральском федеральном округе выявлены 10 частных музеев различных профилей, наиболее встречаемые из них - отраслевые и минералогические музеи, что связано с геогра- 
фическими особенностями территории. Основными формами работы с посетителями являются интерактивная экскурсия и мастер-класс. На территории Уральского федерального округа существуют частные музеи с низкой посещаемостью (до 1 тыс. чел. в год), а также с относительно высокой посещаемостью (до 100 тыс. чел. в год). К наиболее посещаемым частным музеям относятся «Музей-шахта «Березовский» в г. Березовский Свердловской области (10 тыс. чел. в год [4]), Екатеринбургский музей В. Высоцкого в г. Екатеринбург Свердловской области (92,5 тыс. чел. в год [4]), «Дом купца Смирнова (Музей пельменя)» в г. Миасс Челябинской области (12-15 тыс. чел. в год [4]).

В Сибирском федеральном округе выявлены 59 частных музеев. В Восточной Сибири преобладает художественный (изобразительного и декоративно-прикладного искусства) профиль. В Западной Сибири большинство частных музеев рассматриваемой территории принадлежат к историко-краеведческому профилю.

Как правило, частные музеи региона узконаправленные: большинство из них можно отнести к музеям одной темы, явления или предмета («Музей топора», пос. Азъград, Омская область; музей «Каменский ковер», с. Каменка, Тюменская область и др.), а также к музеям «культуры повседневности». («Интегральный музей-квартира повседневности Академгородка», г. Новосибирск и др.).

В тематике коллекций частных музеев прослеживается также уникальная тенденция к фиксации технологии («Музей пчеловодства на Алтае», г. Барнаул; «Музей кузнечного мастерства», г. Тюмень и др.). Среди направлений деятельности практически во всех музеях основным является культурно-образовательное. Формы работы учреждений с посетителями разнообразны, но преобладают традиционные (экскурсии, мастер-классы) с элементами интерактивности (театрализация, контактность с экспозицией и т. д.). Частные музеи Западной Сибири тесно связанны с сохранением самобытности, культуры малых народов («Этнокультурный центр-музей «Кудюр», пос. Кучерла, Республика Алтай; музей-усадьба старообрядческой культуры «Причумышье», с. Залесово, Алтайский край и др.), они являются популяризаторами региональной истории и культуры, что указывает на их важность в контексте музейного мира региона и социокультурного пространства сибирского региона в целом.

В Дальневосточном федеральном округе выявлены 9 частных музеев. В округе в равной степени присутствуют музеи художественного, исторического профилей, а также естественно-научного, отраслевого и комплексного. В частных музеях округа в качестве формы взаимодействия с посетителями применяется классическая экскурсия. Посещаемость частных музеев округа невысокая. Исключение составляет музей вулканов на Камчатке «Вулканариум» в г. Петропавловск-Камчатский Камчатского края (ок. 4 тыс. чел. в год [4]), «Музей Vintage» в г. Владивосток Приморского края (ок. 12 тыс. чел. в год [4]).

Рассматривая частные музеи России в совокупности, можно сделать ряд выводов. Относительно профильной принадлежности частных учреждений культуры наблюдается преобладание исторического (этнографического), художественного, а также отраслевого профилей. Следует выделить тенденцию наличия большого количества частных музеев, сложноотносимых к какой-либо профильной группе. Это связано с тем, что музеи основаны на частных типологических коллекциях. Из 351 выявленного музея к таким можно отнести 54 музея. Например, «Музей ложки» в г. Владимире Владимирской области основан на частной коллекции столовых приборов различных исторических периодов. «Музей спички» в г. Люберцы Московской области представляет систематическую экспозицию спичечных коробков. Данные учреждение можно было бы отнести к отраслевой группе, если бы помимо продукта был продемонстрирован процесс производства.

Существуют также музеи, построенные на коллекции разнородных предметов, но с изображением чего-то определенного, например, «Му-музей» в г. Домодедово Московской области, представляющий собрание предметов (магнитов, игрушек, упаковки, монет, марок, значков и др.) с изображением коров и быков. Учреждения такого рода даже условно сложно отнести к какой-либо профильной группе. Музеи такого рода затруднительно классифициро- 
вать по традиционным, принятым в музееведческой науке, принципам, но возможно по находящемуся в стадии разработки О. С. Сапанжа морфологическому принципу. Согласно данной классификации музеи такого рода относятся к области социальной организации и регуляции. О. С. Сапанжа отмечает, что «музеи и частные собрания кофемолок, самоваров, валенок, утюгов являются выражением стремления зафиксировать стремительные изменения, происходящие именно в сфере хозяйственной культуры, стремительной сменой объектов хозяйственной деятельности человека» [11, с. 10].

Следует также отметить общую тенденцию в тематической направленности частных музеев - многие из них имеют краеведческую направленность, отражают социокультурную специфику региона, но не обладают репрезентативностью в той же степени, что и государственные краеведческие музеи, поскольку имеют, как правило, локальный характер и основаны на узкотематических частных коллекциях.

Основными формами работы с посетителями в выявленных музеях являются традиционные формы: экскурсия и мастер-класс. В большинстве из них применяются также неклассические интерактивные формы работы (квесты, творческие мастерские и т. д.)

Цифровизация частных музеев развита недостаточно на всей территории страны, за исключением нескольких технологичных музеев г. Москвы и г. Санкт-Петербурга. Средняя посещаемость частных музеев в стране невысокая - от 1 до 3 тыс. посетителей в год. Исключением являются крупные частные музеи г. Екатеринбурга, г. Москвы, г. Санкт-Петербурга, а также курортных городов Южного федерального округа. Более высокая средняя посещаемость зафиксирована в Приволжском федеральном округе - около 5 тыс. человек в год.

Таким образом, исследование показало, что группа частных музеев России является важной частью современного музейного мира страны, представленного значительным разнообразием учреждений. При условии преодоления ряда неопределенностей (терминологической, классификационной, правовой и экономической) и при цифровизации частные музеи имеют высокие перспективы развития.

Для решения проблем частного музея на первоначальном этапе необходимо привлечь внимание представителей музейного сообщества страны и региона к проблематике частного музея, организации учёта музейного собрания и его продвижения актуальными средствами музейной коммуникации, с использованием цифровых технологий; осуществить разработку термина «частный музей» и закрепить его путем ввода словари; консолидировать усилия специализированных сообществ частных музеев; продумать механизмы взаимодействия частного музея и региональных властей по их популяризации и продвижению, с одной стороны и по привлечению внимания туристов к уникальному наследию регионов, с другой.

\section{Список литературы}

1. Статистические данные по видам учреждений культуры, искусства и образования // АИС «Статистическая отчетность отрасли». ГИВЦ Минкультуры России : [сайт]. - Москва, 2021. - URL: https://stat.mkrf.ru/indicators/ (дата обращения: 22.03.2021).

2. Колупаева, А. С. Музейный фонд и музеи современной России: нормативно-правовые, финансовые и организационные проблемы функционирования // Культура России. 2000-е годы : [сб. ст.]. Санкт-Петербург : Алетейя, 2012. - С. 225-242.

3. Шехватова, Е. В. Частный музей как культурная форма: теоретические аспекты // Культура и образование. - 2018. - № 3. - С. 20-26.

4. Ассоциация частных и народных музеев России : каталог музейного фонда // Ассоциация частных музеев России : [сайт]. - Москва, 2021. - URL: https://privatemuseums.ru/wpcontent/uploads/2020/03/catalog.pdf (дата обращения: 21.03.2021).

5. Устав международного совета музеев (ИКОМ) : принят на 16-й Ген. Ассамблее ИКОМ 5 сент. 1989 г., доп. и изм. от 9 июня 2017 г./ ИКОМ России : [сайт]. - Москва, 2021. - URL: http://icom-russia.com/upload/documents/Устав\%20ИКОМ_2017.pdf (дата обращения: 20.02.2021).

6. Словарь актуальных музейных терминов // Музей. - 2009. - № 5. - С. 47-68.

7. Кулемзин, А. М. Об определении понятия «музей» // ArtAgeLess.com, портал : [сайт]. - Стерлитамак, 2021-2014. - URL: http://artageless.com/definition-museum (дата обращения: 20.09.2021). 
8. Полякова, Е. А. Развитие музея как образовательной формы культуры // Вестник Томского государственного университета. История. - 2014. - № 6. -С. 129-136.

9. Частные музеи // Российская музейная энциклопедия. Словарь терминов. - Москва, 2009- . URL: http://museum.ru/rme/sci_privat.asp (дата обращения: 10.12.2021).

10.Сапанжа, О. С. От классификации музеев к морфологии музейности: к постановке проблемы // Вопросы культурологии. - 2010. - № 10. -С. 74-77.

11.Сапанжа, О. С. Классификация музеев и морфология музейности: структура и динамика // Вопросы музеологии. - 2012. - № 1. - С. 3-12.

12.О развитии частных музеев в Российской Федерации : решение коллегии Министерства культуры Российской Федерации от 23 сент. 2017 г. № 23 // Министерство культуры Российской Федерации : [офиц. сайт]. - Москва, 2021. - URL: https://culture.gov.ru/documents/o-razvitii-chastnykh-muzeevv-rossiyskoy-federatsii/ (дата обращения: 13.12.2021).

13.Ответ на обращение по вопросу ознакомления с Перечнем (реестром) частных музеев и Программой развития частных музеев заместителя директора Департамента музеев и внешних связей Минкультуры Российской Федерации Н. В. Чечель от 24 марта 2021 г. № 1256-05-08 // Личный архив Е. В. Шехватовой.

14.Неретин, О. П. Год молодёжи в России как фактор социального развития общества // Культура России. 2009 - Год молодёжи : инф.-аналит. сб. / О. П. Неретин, Т. Г. Никольская, Е. Н. Короткая. - Москва, 2009. - 551 с.

15.Тульчинский, Г. Л. Менеджмент в сфере культуры : учеб. пособие/ Г. Л. Тульчинский, Е. Л. Шекова. - Санкт-Петербург : Лань, 2013. - 528 с.

16.Смолев, Д. Рейтинг российских музеев - 2020: когда музеи были офлайновыми. - The Art Newspaper Russia : [сайт]. - Москва, 2021. - URL: https://www.theartnewspaper.ru/posts/8055/ (дата обращения: 23.10.2021).

Evgeniia $V$. Shekhvatova

Altai State Institute of Culture (Barnaul, Russia) 01jenia@mail.ru

\section{CURRENT STATE AND PERSPECTIVES OF PRIVATE MUSEUMS IN RUSSIA}

Abstract. The paper briefly describes the contemporary state of Russian private museums acting as a part of national museum network. The author analyses a set of current problems in theory and practice of Russian private museum sector, such as a need for detailing terminological system, a lack of common criteria for classification of non-state museums, increasing economic risks and indefiniteness in legal regulation for private museums. The paper gives the author's view on definition of term "private museum", outlines data concerning quantitative dynamics of private museums, considers peculiarities of such type of museum institutions.

Keywords: museums of Russia, private museums, museumification, museum network, museum world 